\title{
Escola pública e qualidade de ensino: uma questão de identidade
}

Paulo Sergio Ribeiro'

\section{RESUMO}

O presente trabalho é parte de uma dissertação de mestrado, que se encontra em desenvolvimento e busca oferecer subsídios para uma abordagem e discussão sobre a importância da identidade, do indivíduo e das instituições, na modernidade em face às transformações sociais e políticas da sociedade.

O que buscamos levantar é a hipótese de que uma escola pública com uma identidade sólida pode oferecer uma educação de qualidade, sendo o projeto pedagógico o meio para a construção da identidade, dando estabilidade e qualidade a escola pública.

Palavras-chave: educação, identidade, projeto pedagógico

\section{Introdução}

Ao nosso ver é de grande importância a discussão sobre a identidade da escola pública, pois com a modernidade fica declarada a transitoriedade das instituições e do indivíduo. Mas o termo identidade é de conceito bastante amplo e divergente pois, com a evolução dos tempos, tivermos a cada momento da história um centramento no que seria a identidade do indivíduo e das instituições sociais que interferem na sua formação. Para entendermos os conceitos de identidade precisamos localizar o su-

\footnotetext{
'Professor Colaborador do Departamento de Métodos e Técnicas de Ensino da Universidade Estadual de Ponta Grossa (UEPG). Aluno regular do Progrania de Mestrado (UEPG).
}

Olhar de professor, Ponta Grossa, 3 (3):69-84, nov. 2000. 
jeito, primeiramente no tempo, pois as sociedades modernas são, portanto, por definição, sociedades de mudanças constantes, rápidas $e$ permanentes. Esta é a principal distinção entre as sociedades "tradicionais" $e$ as "modernas" (HALL, 1998, p. 14).

Na sociedade tradicional a identidade baseia-se na pessoa humana com um indivíduo totalmente centrado, unificado e dotado das suas capacidades. O sujeito já nascia com essa identidade e, ao longo da sua vida, ele apenas desenvolvia-a sendo que o centro permanece o mesmo "o centro essencial do eu era a identidade de uma pessoa" (HALL, 1998, p.l1). Essa concepção de identidade nos revela uma visão bastante individualista do sujeito, tornando-o um ser de identidade definida biologicamente.

Em outro momento histórico, um segundo ponto de vista apresenta um sujeito onde a identidade aparece em consonância com o meio, ou seja "é formada na interação entre o eu e a sociedade" (HALL, 1998, p. 11). Com isso começamos a ter um descentramento do indivíduo que, embora tenha um núcleo interior bastante forte, admite-se, na sua interação com a sociedade, uma transformação dessa identidade sendo que, as várias interações socioculturais passam a influenciá-lo.

Nesse sentido, aparece a importância das estruturas sociais na formação do indivíduo, pois como nos diz HALL a identidade então, costura o sujeito a estrutura. Estabilizam tanto o sujeito quanto os mundos culturais que eles habitam, tornando ambos reciprocamente mais unificados e previsiveis (1998, p. 12).

Já com o sujeito modemo são justamente os conceitos descritos, que estão se colocando em discussão e, principalmente, a identidade deste sujeito 'face às várias e rápidas mudanças das estruturas sociais e do meio em que está inserido. $\mathrm{O}$ sujeito que se acreditou unificado começa agora a fragmentar-se e a sua identidade que, definida biologicamente, doravante passa a ser definida historicamente, levando o sujeito a assumir diferentes posturas em relação aos momentos em que vive.

Esse processo produz "o sujeito pós-moderno, conceptualizado como não tendo uma identidade fixa, essencial ou permanente. A identidade torna-se uma 'celebração móvel': formada e transformada continuamente (HALL, 1998,p.13), afetado pela sociedade e a provisoriedade que se instaura na modernidade tardia (segunda metade do século $X X$ ) onde a busca de referências parece ser o que atormenta o homem moderno .

Com as crises de identidades do sujeito são, também, abaladas as Instituições Sociais, afetadas pela modernidade, pelo desenvolvimento dos meios de comunicação, da cultural e do progresso científico desta sociedade. A escola como uma Institui- 
ção social não fica de fora desta instabilidade provocada pelo momento histórico, visto que a discussão sobre a sua função e qualidade vem sendo amplamente debatida nos mais variados estudos científicos e centrando a escola em pontos que fazem parte do seu dia a dia, mas que nem sempre privilegia o todo.

É dessa perspectiva que nos propomos a fazer uma abordagem sobre a identidade do sujeito que compõe a escola, a identidade da instituição enquanto órgão público e atrelado às políticas públicas e procurando identificar os fatores que provocaram o seu descentramento bem como as hipóteses que, na nossa ótica, provocaram na escola pública uma crise de identidade, afetando a sua qualidade e colocando em questão o seu papel na sociedade moderna, além de procurarmos fazer alguns apontamentos sobre como superar esse impasse.

Para tanto procuramos definir como um marco inicial do trabalho, em relação à política educacional, a década de 60 (sessenta) onde verificamos os acontecimentos sociais e políticos mais marcantes na histónia da educação brasileira, pois segundo OLIVEIRA

Só a partir desta década é possível falar em planejamento educacional propriamente dito, com a Lei de Diretrizes e Bases da Educação Nacional no 4024 de 1961 (1997,p. 67) .

Além deste marco educacional, durante esta década ocorreram váni- os fatos, principalmente políticos, que afetaram não só a educação mas toda a vida dos brasileiros que, após a Revolução de Março de 1964 jamais seria a mesma.

A nova organização política do Estado brasileiro, através do governo militar, dá a escola características próprias onde a sua organização lhe conferia uma identidade, esta reconhecidamente a serviço do Estado.

Isso coloca a escola de forma submissa ao poder estabelecido no país, identificando a escola como aparelho ideológico de Estado, que procurava construir a sua hegemonia.

Desta forma no período decorrido ao final da década de 60 (sessenta), 70 (setenta) e início da década de 80 (oitenta), a apropriação da escola por parte do Estado definia os caminhos por ela seguidos e embora tivéssemos mudanças no governo, a diretriz política era ditada pelo sistema militar, o que assegurava uma certa estabilidade ao regime político que, ao nosso ver, mantinha estável as diretrizes da educação brasileira.

$\mathrm{Na}$ escola, durante este período, o que se verifica é uma ênfase na preparação para o trabalho e o país buscava seu desenvolvimento através da industrialização, sendo que para isso precisa de mão de obra especializada.

Verificamos a quebra de um paradigma com a tentativa de superação de um modelo eminentemente agrícola para um industrial, e a escola é peça fundamental para a implan- 
tação do novo modelo de desenvolvimento.

Neste novo paradigma, impera o modelo taylorista - fordista onde o domínio incidia sobre as habilidades de ordem manual uma vez que o processo das linhas de produção requeria, para a época, trabalhadores especializados em tarefas específicas, manuais e repetitivas.

Este paradigma vem de maneira tão forte para dentro da escola que não se limita a simplesmente formar o trabalhador que requer a industria e passa adotar para si o modelo organizacional da industria, com tarefas específicas e hierarquizadas cria a supervisão e orientação de ensino.

Com o desenvolvimento tecnológico e dos meios de comunicação ocorre no durante a década de 80 (oitenta), o processo de democratização do país e as formas de controle do Estado na educação começam a ser questionadas.

Destes questionamentos vemos emergir um novo paradigma para a educação brasileira, principalmente, no início da década de 90 (noventa) onde vemos entrar em evidência novas concepções de Estado, pois temos a implantação de políticas neoliberais no país .

Aliado às novas políticas a escola enfrenta uma nova mudança de paradigma na educação, pois o trabalho manual e a especialização nāơsão mais admitidos como única ferramenta do trabalhador moderno. Esse novo trabalhador precisa além do domínio específico da sua área ter conhecimentos amplos, em todas as áreas, conhecimento de informática e ser criativo. Nesse novo paradigma educacional o trabalho manual é substituído pelo trabalho intelectual e, a importância do conhecimento ganha uma evidência cada vez maior.

Procurando caracterizar esses períodos de evolução histórica de nosso país, a emergência de novos paradigmas para a Educação, tentamos entender o processo em que está inserida a escola pública. Desta forma buscamos justificativas para aquilo que acreditamos ter provocado uma crise e perca de identidade dessa mesma escola.

A busca de uma nova identidade para escola pública passa necessariamente pelo entendimento de quem é o indivíduo no interior da escola, e esta enquanto uma instituição, além dos acontecimentos políticos. Para que possamos encontrar novas perspectivas na construção da identidade desta instituição que já se encontra sob um novo paradigma de educação e de Estado.

O que buscamos levantar é a hipótese de que uma escola pública com uma identidade sólida pode oferecer uma educação de qualidade e estar "a salvo" de projetos educacionais dos períodos eleitorais, muito comuns em nosso país.

É necessário enfatizar que a construção desta identidade deve ser feita no interior da própria escola, através de um trabalho coletivo de todos os 
seus membros, sejam internos ou externos.

Esse trabalho coletivo na escola, conhecido também como projeto pedagógico, ao nosso ver pode tornar a escola realmente uma Instituição de fato e de direito, ao contrário do acontecido no período do regime militar, onde a escola limitava-se a ser uma organização, devida em grande parte à centralização do trabalho e a presença àcritica dos seus membros.

\section{A identidade do sujeito na modernidade}

Antes de iniciarmos a discussão sobre a identidade do sujeito procuramos caracterizar o período em que nos encontramos, bem como a nossa opção pelo termo modernidade.

A modernidade, segundo LYON, parte da contestação das bases do pensamento tradicional, com o questionamento e a sua procura de progresso, visto muitas vezes como desenvolvimento, que teve o seu auge compreendido entre

1789-1989 tornaram-se assimo período simbólico de dois séculos de modemização, expresso politicamente como a busca de um mundo racionalizado - da Revolução Francesa à queda do socialismo e do estado burocrático (LYON, 1998, p. 16).

Com isso temos a modernidade caracterizada.

Mas quem é o sujeito no período histórico em que vivemos? Devemos estar atentos a todas as possibilidades de influência na escola que, embora sendo uma Instituição e tenham o seu papel definido na sociedade, sofre a inferência dos sujeitos. No cumprimento das suas funções, os sujeitos, através dos seus atos pedagógicos, nas instituições, são de relevante importância para entendermos esse espaço chamado escola.

Em nosso ponto de vista, nas atitudes do professor estão pontos imprescindíveis para o sucesso de qualquer sistema educacional. Como destaca ESTEVE

as atitudes do professor e da sociedade são fundamentais para realizar as reformas que se projetam. Na atitude dos professores perante as reformas eo apoio da sociedade está a chave para levar a bom termo. Sem o seu incondicional apoio não passaräo de terreno das disposições legais ao terreno da realidade: o trabalho cotidiano da sala de aula (1995, p. 16).

Este saber tácito do sujeito/educador não pode e não deve ser desprezado e com a importância do trabalho coletivo na escola, acreditamos que o educador precisa saber quem é, e neste ponto vemos a grande importância da formação inicial, pois este sujeito trás consigo arraigado em sua personalidade valores, crenças, sua identidade e as suas referências construídas durante a sua formação inicial. 
Assim tentaremos identificar, de maneira sucinta, quem é o sujeito na modernidade e como ele chegou a esta identidade, a importância da sua prática pedagógica e de seu saber para o processo educacional.

Procuramos nos colocar em relação à identidade do sujeito sob dois aspectos: o primeiro enfocando o sujeito, os conceitos que procuraram definir a sua identidade até o período da modernidade e a fragmentação das identidades no período moderno que, segundo alguns autores (HALL ${ }^{2}$, 1998; LYON $^{3}, 1948$; TOURAINE ${ }^{+}$, 1925 ) ocorre devido às mudanças constantes de nossa sociedade.

Em um segundo aspecto referimonos às instituições en que este sujeito está inserido e que compõem a sociedade, procurando discutir a possibilidade de definição de identidade da instituição e, enquanto tal, se é possível que venha a ter uma identidade própria que lhe garanta confiabilidade, respeito e, principalmente, no caso da escola pública qualidade no cumprimento das suas atribuições.

Segundo o dicionário brasileiro, identidade é, em relação ao sujeito, o "reconhecimento de que um indivíduo é o próprio"s. Vemos que nessa defi- nição está o reforço da complexidade do tema pois remete o sujeito a ele mesmo, nos revelando que a identidade é algo implícito no próprio ser. Essa afirmação remete-nos à indagação: que importância tem as interferências do meio e as constantes mudanças da sociedade na determinação de quem são os sujeitos?

$\mathrm{Na}$ nossa visão a sociedade desempenha um papel importante no centramento de quem é o sujeito e procuramos deixar claro, a necessidade de contextualização do sujeito em relação ao tempo e espaço em que vive, pois acreditamos na influencia do meio sobre o indivíduo.

A esse respeito HALL (1998, p. 11) estabelece três distinções do que seria a identidade em cada período da história que são: o sujeito do iluminismo, o sujeito sociológico e o sujeito moderno.

No sujeito do Iluminismo (relacionada como uma concepção tradicional) a identidade baseava-se na pessoa humana, uma vez que o indivíduo já nascia com a sua identidade $\mathrm{e}$ a desenvolvia através dos tempos, sendo algo interior de cada um, sendo o sujeito centrado, unificado e dotados das suas capacidade e de sua

${ }^{2}$ HALL, Stuart - A identidade cultural na pós-modernidade / Stuart Hall; Tradução Tomáz Tadeu da Silva, Guaracira Lopes Louro-2. Ed. - Rio de Janeiro : DP\&A, 1998.

${ }^{3}$ LYON,David, 1948 - Pós-modernidade / David Lyon; - Traduçāo Euclides Luiz Calloni - São Paulo: Paulus, 1998. - (Temas da Atualidade)

+ TOURAINE, Alain, 1925 - Crítica da modernidade / Alain Touraine : Tradução Elia Ferreira Edel. - Petrópolis, Rj: Vozes, 1994.

${ }^{5}$ Dicionário Brasileiro Globo $48^{\circ}$ edição - 1997 
identidade "o centro essencial do eu era a identidade de uma pessoa" ( Hall, 1998, p. 11).

Os iluministas baseados nas suas idéias de homem racional, científico, libertado do dogma e da intolerância e, diante do qual se estendia a história humana para ser compreendida $e$ dominada, apresentam uma visão bastante individualista da pessoa humana; este sujeito representa uma ruptura importante com o passado. As transformações que se seguiram vieram libertar o indivíduo de seus apoios estáveis que eram as estruturas e as tradições e muitos movimentos de pensamento e na cultura ocidental que contribuíram para emergência de novas concepções como : a Reforma ${ }^{6}$, o Protestantismo ${ }^{7}$, o Humanismo Renascentista $^{8}$ e o Iluminismo ${ }^{9}$. Na nossa ótica o grande descentramento dá-se, nesse período, com o deslocamento de Deus do centro do Universo e a colocação do homem ao centro, isso provocado justamente pelas revoluções científicas que deram ao indivíduo a capacidade de pensar, investigar e decifrar os fenômenos da natureza.

HALL (1998), aponta esse como sendo o inicio do descentramento do sujeito, embora o pensador francês René Descartes (1596-1650), atingido pelo deslocamento de Deus do centro do Universo postula duas substâncias distintas a substância espacial (matéria) e a substância pensante (mente) e coloca no centro da mente o sujeito individual, constituído por sua capacidade de pensar.

Descartes, faz essa distinção mas mantém a possibilidade para o sobrenatural ou Divino na concepção do homem e da sua identidade, mas o dualismo cartesiano contribui para o aparecimento do sujeito sociológico.

Já na visão sociológica o sujeito tem um núcleo de essência interior, mas é constantemente modificado pelo mundo exterior. Portanto passase a admitir uma interferência de fora na formação da identidade do indivíduo. Nessa perspectiva aparece de maneira importante as instituições ou estruturas da sociedade, pois

a identidade então, costura o sujeito a estrutura. Estabiliza tanto

\footnotetext{
${ }^{6}$ Reforma: movimento social que se caracteriza por respeitar a ordem estabelecida e procura corrigir os desajustes para trazer a realidade o modelo tradicional

${ }^{7}$ Protestantismo: designação genérica de numerosas igrejas cristãs que compartilham princípios comuns, como a autoridade da Bíblia e a salvação pela fé. Movimento surgido ao longo do século XVI.

${ }^{\text {B } H u m a n i s n o: ~ m o v i m e n t o ~ i n t e l e c t u a l ~ e ~ c o n c e p c ̧ a ̄ o ~ f i l o s o ́ f i c a ~ q u e ~ a p r e s e n t a m ~ o ~ h o m e m ~ c o m o ~ o ~}$ centro do universo. Surgido na Europa no século XIV.

'Iluminismo: movinıento cultural e intelectual, surgido na Europa, no século XVIII, baseado no uso e exaltação da razão. Considerava o conhecimento, a liberdade e a felicidade os objetivos do homem.
} 
os sujeitos quanto os mundos culturais que eles habitam, tornando ambos reciprocamente mais unificados e prediziveis (HALL, 1998, p. 12)

mas não abandona por completo a visão da identidade como algo interior e definido biologicamente, procurando mostrar as influências dos grupos sociais na formação do indivíduo e mostrando a interatividade entre o "externo" e o "interno".

Essa visão do relacionamento indivíduo - sociedade é apoiada nas reflexões de como o "eu" se comporta nas mais diferentes situações sociais, pois de acordo com cada uma delas a tendência é que o indivíduo venha a adaptar-se, o que colocaria em xeque a sua autenticidade ou sua identidade, em uma visão tradicionalista de identidade.

Com a afirmação do sujeito sociológico procuramos demonstrar a importância das estruturas sociais na formação da identidade do indivíduo. Alguns críticos como HALL afirmam que

a sociologia convencional mantivera algo do dualismo de Descartes, especialmente em sua tendência para construir o problema como uma relação entre duas entidades conectadas mas separadas : aqui o "individuo e a sociedade" (1998.p. 32),

mas os maiores descentramentos estavam apenas começando pois estava por vir a modernidade .

O que é a modernidade, se não o questionamento das bases estabelecidas pelas idéias tradicionais, onde a contestação dos dogmas e das idéias de "providência Divina" dá lugar ao técnico e o científico? Como diz TOURAINE

A modernidade é a antitradição, a derrubada das convenções, dos costumes e das crenças, a saída dos particularismos e a entrada do universalismo ou, ainda a saída do estado natural a a entrada na idade da razão.(1994; p. 216).

Com a modernidade, esses conceitos são colocados em questão pois, segundo ela, o sujeito não tem uma identidade fixa uma vez que tudo está em movimento, inclusive a identidade, que é constantemente interpelada pelas interaçōes sociais, pela velocidade das transformações produzidas, pela rapidez das informações e mudanças de valores que relativizaram o sujeito e as suas relações. A diversidade cultural $\mathrm{e}$ as diferenças que na cultura tradicional estavam bastante distantes, hoje fazem parte da vida de todo o cidadão, tornando-o sujeito da história. Isso nos leva a inferir que na visão da modernidade a identidade não é mais uma questão determinada de forma biológica mas sim definida historicamente.

Afetado pelos mesmos acontecimentos do sujeito cartesiano, o que acontece com o indivíduo na modernidade é o seu deslocamento pois há a passagem de um sujeito centrado com uma identidade fixa a um sujeito moderno com uma identi- 
dade fragmentada. Isso não se deu de uma forma simplista na evolução do homem; vários acontecimentos, descobertas e movimentos sociais contribuíram para fragmentar o sujeito provocando o seu o descentramento.

Entretanto é necessário relacionarmos sumariamente alguns acontecimentos que, segundo HALL, contribuíram de forma decisiva para o descentramento do sujeito cartesiano, para nos localizarmos em relação à definição de sujeito da modernidade.

O pensamento marxista, onde os "homens fazem a história, mas somente de acordo com as condições quem lhes são dadas", (HALL, 1998; p.34) esta visão coloca o indivíduo a mercê do meio em que está inserido e condição cultural ao qual pertence, deslocando qualquer condição de ação individual $\mathrm{e}$ independente.

Nas descobertas de FREUD, sobre o inconsciente em que a identidade, a sexualidade e os desejos são formados em processos psíquicos e simbólicos de nosso inconsciente, e a identidade se torna algo formado ao longo do tempo.

No trabalho do lingüista estrutural SAUSSURE onde afirma que a língua "é um sistema social e não individual . Ela preexiste a nós . Não podemos em qualquer sentido simples ser os seus autores"(HALL, 1998, p.40), em relação a identidade se define por referências intrincicas, ou seja pela negação do outro sei quem sou por não ser o outro.

Nas descobertas de FOUCAULT onde destaca um novo tipo de poder o "poder disciplinador" e alerta para o paradoxo que quanto mais coletiva e organizada a instituição maior o isolamento e individualização do sujeito.

O impacto do movimento feminista, tanto como uma crítica teórica como um movimento social, questionou a noção de que os homens e as mulheres eram parte da mesma identidade a "Humanidade", substituindo pela questão da diferença sexual .

Os descentramentos descritos, segundo HALL, acabaram por produzir um sujeito com identidades abertas, contraditórias, inacabadas e fragmentadas ocasionadas pela influência dos acontecimentos à produção de efeitos desestabilizadores sobre as idéias da modernidade e a sua forma de ver o mundo.

Afirma-se, cada vez mais, a necessidade contextualização do sujeito e a sua identificação com as instituições sociais, vendo nascer um novo homem e a sua interação com o meio, sua identificação com o outro mas preservando o seu senso crítico e a capacidade de discernimento das verdades que se apresentam em todo o seu momento histórico e o seu comprometimento com as Instituições sociais.

Os sujeitos modernos são históri$\cos$, ou seja, constróem a sua história e das suas Instituições no seu dia a dia e o seu saber tácito é de grande relevância para as soluções dos problemas pelo qual atravessam algumas 
instituições públicas como, por exemplo, a escola .

Com a sua identidade aberta e inacabada o sujeito necessita que a Instituição tenha o seu projeto definido para que possa atuar de forma decisiva no cumprimento do papel desta Instituição determinado pela sua identidade. O projeto de escola, conhecido hoje como o Projeto Político Pedagógico, pode auxiliar este sujeito de identidade fragmentada a desempenhar o seu papel nas Instituições no cumprimento do papel que lhe é atribuído pela sociedade da nossa época .

Desta forma é necessário que o sujeito tenha a sua identidade definida, mas é possível que a Instituição tenha uma identidade definida para dar sustentação ao sujeito?

\section{$A$ identidade $e$ as instituições}

Como a identidade do sujeito está fragmentada, sendo determinada pelo momento histórico em que atravessa , começa a ter destaque as instituições e organizações que este sujeito participa, entre elas a escola pública que, ao nosso ver entra em un processo de descaracterização ao longo do tempo. Isso se deve á vários processos históricos que descentraram o indivíduo e que, de forma não diferente também, afetaram as instituições e o seu objeto de trabalho que está em constante mutação. $O$ conhecimento paralelo $\mathbf{a}$ isso as discussões sobre a qualidade das instituições e a sua reorga- nização também deram conta de produzirem efeitos dentro que à afetaram profundamente.

Portanto procuremos estabelecer um paralelo das crises de identidade produzidas pela modernidade e o que acreditamos acontecer com a Escola Pública, principalmente no final da década de sessenta inicio da década de setenta. Nesse contexto as polarizações dos vínculos étnicos, religiosos ou de classes, que produzem identidades alternativas que seriam inapropriáveis pelo Estado, deveriam garantir a escola uma identidade não diria fixa, mais menos vulnerável ao ataque ideológico pôr parte daqueles que determinam as políticas publicas. Mas segundo SANTOS o que aconteceu foi o inverso, ou seja, houve uma apropriação pôr parte do Estado do discurso demostrando a sua capacidade de reversão dos quadros que não lhe são favoráveis de forma rápida e efetiva na defesa dos seus interesses.

Afirma ainda:

A verdade, porém ,é que nenhum desses vinculos logrou fazer vingar; uma altemativa concreta, nem no plano político, nem mesmo no plano sociocultural. Pelo contrário , o vínculo individuo-Estado, assente na obrigação político-liberal, não cessou de afirmar a sua hegemonia e, por processos diferentes, foi-se apropriando do potencial alternativo dos demais vínculos, que assim descaracterizados acabaram por ser postos ao serviço da lealdade 
terminal do Estado (SANTOS, 1995,p. 141).

Com a impossibilidade desses vínculos defenderem os seus interesses, o Estado apropria-se da Educação como forma eficiente de manter a sua hegemonia tornando a escola aparelho ideológico do Estado, onde o seu controle era eficiente favorecido pelo momento histórico e político vivido na época.

Nessa perspectiva lembramos que no período citado o paŕs vivia sob o regime militar e pela própria concepção de Estado ${ }^{10}$ controlava e controla, a maior parte das inciatívas na área da educação, em que as políticas públicas eram aplicadas de forma que $o$ governo tinha sobre a rede de ensino quase que um total controle e a educação revela-se com uma identidade inconfundível "a serviço do Estado" e a efetivação das suas políticas. Nesse período temos uma política bem definida e que defendia os interesses do Estado através de suas Leis Federais que determinavam a política para a educação. Neste ponto nada difere dos dias de hoje, porém havia um processo de continuidade que assegurava que a ideologia contida nas leis fosse levada a cabo pelos que estavam a serviço de um sistema que advogava em direito próprio.
Com a estabilidade do sistema político e ideológico a identidade da escola e dos seus atores estava a salvo, pois havia uma política definida , um campo de atuação limitado, processos burocratizados de controle e uma limitação dos papéis pessoais dentro da instituição, era tido como algo fixo, sendo na verdade uma organização que tomava a estrutura da escola um

organismo complexo e rígido pela burocracia existente; as pessoas ocupam cargos hierarquizados nesta estrutura; as funções $e$ ações são normatizadas pôr leis, decretos, regimentos, etc. ; pelo cumprimento excessivo do administrativo, que leva a não priorizar o seu objetivo principal, o pedagógico. (...) vive-se dentro de uma linha funcionalista onde todos trabalham para um objetivo comum estabelecido externamente (SCHMIDT, 1989, p. 27,28).

Essa análise revela um pouco da escola neste período e a sua dificuldade de avanço, pois organizada para atender as demanda de uma sociedade hierarquizada, em que a definição da conduta de seus membros era definida de acordo com a política central, delimitando os papéis daqueles que desempenhavam as funções den-

\footnotetext{
${ }^{10}$ Estado: aqui visto no conceito de Gramsci, onde o Estado se identifica com Governo, com o aparelho de ditadura de classe, ma medida em que ele possui funçōes coercitivas e econômicas. A dominaçāo de classe se exerce através do aparelho de Estado no sentido clássico (exército, polícia, administração, burocracia). O período referido vai de 1964-1984.
} 
tro da instituição inferimos que a escola não era uma instituição, mas uma organização a serviço dos Estado.

Tal inferência se deve à definição de instituição nos estudos de SCHMIDT quando afirma que as instituições deverão ser

constituídas pôr pessoas que se agrupam, interagem, se organizam e se instituem. Possuem com isso o poder de institucionalizar novas formas de ação dentro do que já está constituído (1989. p. 27)

Procurando olhar a escola pública sob esse prisma, algumas indagações são inevitáveis: qual a real função da escola neste período? A quem se destinava a escola pública e a quem realmente servia?

Quando observamos as definições de SCHIMDT a respeito de instituição e organização considerando o momento histórico, pensamos que a escola somente se tornará uma instituição à medida que o processo democrático chegar ao seu interior e que o seu objetivo em relação a todas as classes seja o mesmo e a educação seja um processo emancipação para todos.

O Estado que na época vivia sob o regime militar mantinha suas políticas de forma efetiva pois eram políticas de Estado" determinadas a partir de diretrizes centralizadas e que o regime de Governo ${ }^{12}$ asseguravam o cumprimento de suas normas, imprimindo assim uma identidade ao sistema de ensino através da sua continuidade.

Mesmo identificando algumas mudanças de Governos o seu sistema político mantinha-se estável, pois continuava sendo um regime militar com as mesmas diretrizes filosóficas e ideológicas anteriores. Essa estabilidade do sistema político, ao nosso ver, assegurava o processo de continuidade que ao longo do tempo imprimiu a identidade da escola pública identificando-a com a sociedade da época, nesta perspectiva todos estavam a salvo; pois o governo decidia quem deveria pensar o e o que deveria ser pensado através do controle da produções científicas e literárias da período ${ }^{13}$.

Com a modernidade e a rapidez no processamento das informações, bem como na sua difusão, começa a ocorrer no país um processo de mudança e o sistema político é o primeiro a sentir os efeitos da mudança. $\mathrm{Na}$ segunda metade da década de oitenta encerra-se o período de governo militar dando início ao processo democrático com a participação popular:

Esse é um dos primeiros acontecimentos que provoca o descentramento da identidade até então fixa da escola pública, pois à medida que o processo democrático avança no campo políti-

\footnotetext{
"Estado: aqui visto como naçāo.

'Governo: constituído pelo Estado-naçāo para assegurar o seu poder hegemônico.

${ }^{13}$ Período do governo militar no Brasil 1964-1984.
} 
co e as demandas sociais também reclamam o seu atendimento, a escola começa a abrir-se para uma nova clientela a qual nem mesmo ela talvez estivesse preparada para receber.

Como se não bastasse o crescimento da demanda de forma assustadora e rápida, a escola devido ao processo democrático, mesmo estando ainda subordinada aos planos e diretrizes do Estado, passa a enfrentar o problema de estar aliada aos planos de governo. A sua continuidade assegurada pela estabilidade do regime político do período militar não existe mais; portanto, o que era fixo começa a deslocar-se através do sistema político, e com a abertura política, começamos a identificar outros fatores que virão a provocar, ao nosso ver, mais descentramento, confundindo a identidade da escola .

Com esse processo que se dá em nível de Brasil, verificamos, ao final da década de oitenta, uma grande produção de conhecimento baseados em novas filosofias e ideologias, sociais e políticas, propiciando o surgimento de novas propostas pedagógicas além daquelas trabalhadas. $O$ fato se deve também ao retorno ao país de vários professores que faziam seus cursos de pós-graduação em outros países e que, ao retornarem retomam os seus trabalhos nas Universidades produzindo conhecimento sob um novo prisma. Saindo de um conceito funcionalista da educação que tinha os seus compromissos na manutenção estrutural, cultural e na hegemonia do status quo vigente tendo suas raízes nas teorias positivistase evolucionistas.

O novo conhecimento produzido por estes mestres tem as suas raízes baseada nas teorias críticas e libertárias que buscam, segundo SANDER (1995) uma posição mais crítica, reflexiva e dialética com a preocupação fundamental da emancipação humana e a transformação social.

Com isso identificamos, mais um grande descentramento que produziu efeitos devastadores na escola pública, pois com a mudanças da base do pensamento temos uma real quebra de paradigma, o que anteriormente se verificava de forma fictícia, agora vinha com toda a força e duvidas do novo. Os professores apropriaram-se do discurso de teorias críticas, quando nos parece não estarem preparados para a sua prática.

O que verificamos na prática é justamente o oposto àquilo que se pretendia, houve uma apropriação do discurso sem uma mudança da prática. Como fazer as mudanças práticas acontecerem na mesma velocidade que as produções teóricas?

Outro ponto que não foi levado em consideração foi a forma como as mudanças foram propostas pois, ao contrário das teorias positivistas que tinham todo o seu pensamento e processo metodológico além das avaliações estruturadas devido ao seu pragmatismo, as teorias críticas vieram com uma proposta de discussão da nossa realidade e a sua re-interpretação a luz do nosso momento histó- 
rico, como é no processo dialético de construção do conhecimento e das práticas pedagógicas.

Como não tínhamos o hábito da participação coletiva uma vez que o Estado sempre pensou as práticas para o professor, em face aos seus objetivos, o que verificamos foi mais um descentramento que, ao nosso ver contribuiu para a perda da identidade da escola pública.

Mas como dar a escola pública a sua identidade? O que vai determinar esta identidade? No nosso entender é o projeto pedagógico da escola que em função da articulação com as políticas públicas e sendo determinados pelos sistemas de governo é, também, político.

O projeto político-pedagógico construído com base nas teorias críticas , pode dar a escola uma identidade, mesmo estando ela vinculada aos planos de governo e sujeita as mudanças organizacionais do seu sistema político. Se a escola conseguir tornarse uma Instituição, através do seu projeto, isso pode lhe assegurar uma identidade o nos faz crer que torne difícil a sua apropriação pôr parte do Estado. Estaremos desenvolvendo projetos dentro de um plano micro, sendo que as diretrizes principais estarão em conformidade com o plano macro, estabelecido pela Constituição Federal e pela Lei de Diretrizes e Bases da Educação Nacional . Mas o que,é o projeto político-pedagógico?

Este projeto que visa a construção de uma escola mais autônoma, demo- crática, participativa e cidadã, pode atingir os seus objetivos a medida que propõe um processo coletivo de construção, através do comprometimento dos seus participantes.

Para que estes pensamentos a cerca do projeto político-pedagógico sejam válidos é necessário que ele tenha funções superadoras como no pensamento de VEIGA, quando nos diz que :

o projeto político pedagógico vai além de um simples agrupamento de planos de ensino e de atividades diversas. O projeto não é algo construído e em seguida arquivado ou encaminhado as autoridades educacionais como prova do cumprinento de tarefas burocráticas. Ele é construído e vivenciado em todos os momentos, por todos os envolvidos com o processo educativo na escola (1995, p.12, 13).

Esta constıução e vivênciamento por parte de toda a escola, nos faz crer que o projeto construído de forma coletiva e comprometida pode ser o principal articulador no sentido de definir a identidade da escola pública.

Con uma escola com uma identidade bem definida, considerando essa identidade com um núcleo bastante forte que a caracterizaria, podendo julgar melhor os projetos e tendências pedagógicas, o que the daria condições para avançar sem comprometer a sua qualidade. Estando a salvo até mesmo de planos de governos em 
períodos eleitorais, o que é corriqueiro em nossos tempos de política educacional indefinida e da presença de planos estanques com objetivos imediatistas e sem compromissos para com os que da escola pública necessitam.

Para MARTINS, quando nos fala da escola capaz de construir o seu projeto pedagógico acredita que este seja uma idéia preciosa porque consolida a escola como o lugar central da educação, numa visão descentralizada do sistema; oferece garantia visivel e sempre aperfeiçoável da qualidade esperada no processo educativo (In VEIGA, 1998,p.50).

Como podemos ver há uma esperança bastante grande na construção e efetivação do projeto político pedagógico na escola. Por ser o assunto de grande relevância o consideraremos no próximo capítulo de nosso estudo, com o aprofundamento que o tema requer.

\section{REFERÊNCIAS BIBLIOGRÁFICAS}

1 DICIONÁRIO BRASILEIRO Globo $48^{\circ}$ edição - 1997.

2 ESTEVE, J. M. Mudanças sociais e função docente. In: NÓVOA, A. Profissão Professor. 2.ed. Porto: Porto Editora, 1995.

3 HALL, Stuart. A identidade cultural na pós-modernidade/
Stuart Hall; tradução Tomáz Tadeu da Silva, Guaracira Lopes Louro - 2.ed. - Rio de Janeiro : DP\&A 1998.

4 LYON,David. 1948. Pósmodernidade / David Lyon; Tradução Euclides Luiz Calloni. São Paulo : Paulus, 1998. - (Temas da Atualidade) .

5 MARTINS, Rosilda Baron. Educação para a cidadania: o projeto político-pedagógico como elemento articulador. In :VEIGA, Ilma Passos A. (org.),_Escola : Espaço do projeto político-pedagógico. Campinas, SP : Papirus, 1998. 6 OLIVEIRA, Dalila Andrade. (org.) Gestão democrática da educação: desafios contemporâneos. Petrópolis, Rj: Vozes, 1997.

7 SANDER, Benno. Gestão da educação na América Latina. Campinas: Autores Associados, 1995.

8 SANTOS, Boaventura de Sousa. Pela mão de Alice: o social e - político na pós Modernidade - São Paulo , Cortez, 1995.

9 SCHMIDT, Leide Mara - ${ }^{-A}$ instituição escola numa perspectiva de renovação. Dissertação de mestrado - Pontifícia Universidade Católica - São Paulo - 1989.

10 TOURAINE, Alain, 1925. Crítica da modernidade / Alain 
Touraine : Tradução Elia Ferreira Edel. Petrópolis, Rj: Vozes, 1994.

11 VEIGA, Ilma Passos A. - Projeto político-pedagógico da escola: uma construção possível. Campinas SP - Papirus - 1995. 